\title{
Atratividade para adultos e preferência para oviposição de Bemisia tabaci (Genn.) biótipo B (Hemiptera: Aleyrodidae) em genótipos de Cucurbita spp
}

\author{
Adult attractiveness and non-preference for oviposition of \\ Bemisia tabaci (Genn.) biotype B (Hemiptera: Aleyrodidae) in \\ genotypes of Cucurbita spp
}

\author{
Ronelza Rodrigues da Costa Zaché1*; Edson Luiz Lopes Baldin²; Bruno Zaché ${ }^{3}$
}

\section{Resumo}

\begin{abstract}
Objetivou-se avaliar a preferência para oviposição e a atratividade de genótipos de aboboreiras (Cucurbita spp.) frente à Bemisia tabaci biótipo B. Para os bioensaios, foi mantida uma criação de $B$. tabaci biótipo B em casa de vegetação. Vinte genótipos de Cucurbita spp. ('Alicia AF 9354', 'Aline AF 9353', 'Golden Delight', 'Nova Caravela', 'Menina Morena', 'Novita', 'AF- 6741', 'Atlas', 'Bárbara 305', 'Menina Brasileira', 'Caserta', 'Itapuã 301', 'Tâmara', 'Samira', 'Canhão Seca Gigante', 'Exposição', 'Novita Plus', 'Daiane', 'Formosa', 'Sandy') foram avaliados em ensaios (atratividade e oviposição com chance de escolha), sob condições de laboratório e casa de vegetação. A atratividade (adultos $/ \mathrm{cm}^{2}$ ) foi avaliada 12, 24, 48 e 72 horas após a liberação. Após 72 horas foram coletadas folhas para a contagem do número de ovos (com chance de escolha). As áreas das folhas foram medidas a fim de se obter o número de ovos $/ \mathrm{cm}^{2}$ e o número de adultos $/ \mathrm{cm}^{2}$. O índice de atratividade (IA) e o índice de preferência para oviposição (IPO) foram calculados, sendo o genótipo 'Novita' adotado como padrão suscetível. 'Sandy' 'Daiane' e 'Formosa' apresentaram baixa atratividade, sendo 'Golden Delight' o mais atrativo aos adultos de B. tabaci biótipo B. 'Sandy', 'Exposição', 'Daiane', 'Atlas', 'Tâmara' e 'Formosa' expressaram não-preferência para oviposição no ensaio com chance de escolha. De acordo com o índice de atratividade (IA), entre os repelentes, destacaram-se 'Sandy', 'Daiane', 'Formosa', 'Novita Plus', 'Atlas', 'Bárbara 305', 'Canhão Seca Gigante' e 'Menina Brasileira', enquanto o genótipo 'Golden Delight' foi classificado como o mais atrativo a adultos de $B$. tabaci biótipo B. Segundo o índice de preferência para oviposição (IPO), os genótipos 'Sandy', 'Exposição', 'Daiane', 'Atlas', 'Tâmara', 'Formosa', 'Menina Morena'e 'Itapuã 301' foram considerados deterrentes, enquanto 'Nova Caravela', 'Golden Delight', 'Aline AF 9353' e 'Samira', estimulantes.
\end{abstract}

Palavras-chave: Resistência de plantas, mosca-branca, aboboreira, Cucurbitaceae

\begin{abstract}
The objective was to evaluate the oviposition preference and attractiveness of squash genotypes (Cucurbita spp.) to Bemisia tabaci biotype B. For bioassays, B. tabaci rearing biotype B was kept under greenhouse conditions. Twenty genotypes of Cucurbita spp. ('Alicia AF 9354', 'Aline AF 9353',
\end{abstract}

\footnotetext{
${ }^{1} \mathrm{Dr}^{\mathrm{a}}$ em Agronomia, Proteção de Plantas, Dept ${ }^{\circ}$ de Entomologia DEN, Universidade Federal de Lavras, UFLA, Lavras, MG. E-mail: ronelzagro@yahoo.com.br

${ }^{2}$ Prof. Dr. do Dept ${ }^{\mathrm{o}}$ de Produção Vegetal, Faculdade de Ciências Agronômicas de Botucatu, FCA/UNESP, Botucatu, SP. E-mail: elbaldin@fca.unesp.br

${ }^{3}$ Dr. em Agronomia, Proteção de Plantas, Dept ${ }^{0}$ de Produção Vegetal Faculdade de Ciências Agronômicas de Botucatu/FCA/ UNESP, Botucatu, SP. E-mail: bzache@bol.com.br

* Autor para correspondência
} 
'Golden Delight', 'Nova Caravela', 'Menina Morena', 'Novita', 'AF-6741', 'Atlas', 'Bárbara 305', 'Menina Brasileira', 'Caserta', 'Itapuã 301', 'Tâmara', 'Samira', 'Canhão Seca Gigante', 'Exposição', 'Novita Plus', 'Daiane', 'Formosa', 'Sandy') were evaluated in trials (attractiveness and oviposition choice), under laboratory and greenhouse. The attractiveness (adults $/ \mathrm{cm}^{2}$ ) was assessed et 12, 24, 48 and 72 hours after release. After 72 hours leaves were collected for counting the number of eggs (free choice). The area of the sheets were measured to obtain the number of eggs $/ \mathrm{cm}^{2}$ number of adults and $/ \mathrm{cm}^{2}$. The attractiveness index s (AI) and oviposition preference index (OPI) were calculated, and the genotype 'Novita' was adopted as the standard susceptible. The genotype 'Golden Delight' was the most attractive to adults of B. tabaci biotype B. 'Sandy' 'Daiane' and 'Formosa' showed low attractiveness and 'Golden Delight' was the most atractive to B. tabaci biotype B adults. 'Sandy', 'Exposição', 'Daiane', 'Atlas', 'Tamara' and 'Formosa' expressed no preference for free choise assay. According to the attractiveness index (AI) the genotype 'Golden Delight' was the most attractive to adults of $B$. tabaci biotype B, and between repellents stood out 'Sandy', 'Daiane', 'Formosa', 'Novita Plus', 'Atlas', 'Bárbara 305', 'Canhão Seca Gigante' and 'Menina Brasileira'. The genotypes 'Nova Caravela', 'Golden Delight', 'Aline AF 9353' and 'Samira' are considered by stimulating oviposition preference index (OPI), while the genotypes 'Sandy', 'Exposição', 'Daiane', 'Atlas', 'Tâmara', 'Formosa', 'Menina Morena' and 'Itapuã 301 ' were considered deterrents.

Key words: Resistance of plants, whitefly, squash, Cucurbitaceae

\section{Introdução}

As cucurbitáceas ocupamlugar de destaque dentre as hortaliças no Brasil, sendo sua produtividade prejudicada pela ocorrência de inúmeras pragas, doenças e desordens fisiológicas (BLANCO; GROPPO; TESSARIOLI NETO, 1997).

Entre os insetos-praga de ocorrência em cucurbitáceas destaca-se a mosca-branca, Bemisia tabaci (Genn.) biótipo B, também denominada $B$. argentifolii Bellows \& Perring (VAN LENTEREN; NOLDUS, 1990; BYRNE; BELLOWS JÚNIOR, 1991; LIU; OETING, 1993; OLIVEIRA; SILVA, 1997; VILLAS BÔAS et al., 1997; SUMMERS; STAPLETON, 2002).

A incidência de populações de $B$. tabaci biótipo B em aboboreiras (Cucurbita spp.) geralmente está associada ao prateamento-dasfolhas (LOURENÇÃO; NAGAI, 1994; FRANÇA; VILLAS-BÔAS; BRANCO, 1996; SUMMERS; STAPLETON, 2002; ALVES; LOURENÇÃO; MELO, 2005). Essa anomalia, também reportada como desordem fisiológica, ocorre devido à alimentação de ninfas e adultos dessa mosca-branca, que durante o processo de alimentação injetam toxinas (YOKOMI; HOELMER; OSBORNE, 1990a, 1990b; HOELMER; OSBORNE; YOKOMI,
1990, 1991; DE BARRO et al., 2011), provocando queda na produtividade e deixando os frutos descoloridos em relação aos normais (NAGAI et al., 1992). Os sintomas aparecem de três a cinco dias após a exposição de folhas às ninfas (YOKOMI; HOELMER; OSBORNE, 1990a; HOELMER; OSBORNE; YOKOMI, 1990, 1991) ou nove a onze dias após a exposição a adultos (HOELMER; OSBORNE; YOKOMI, 1990, 1991; DE BARRO et al., 2011).

Segundo Flint (1995), Villas Bôas et al. (1997) e Norman et al. (1996), ninfas e adultos da moscabranca ao se alimentarem das plantas, sugam a seiva, injetam saliva nos tecidos e retiram nutrientes, podendo ocasionar redução no crescimento, desfolha, diminuição da produtividade e até a morte das mesmas.

Outro dano seria o aparecimento da fumagina, com o desenvolvimento do fungo Capnodium spp., devido à excreção de honeydew, prejudicando a fotossíntese, causando perda da qualidade do produto final (FLINT, 1995; VILLAS BÔAS et al., 1997; NORMAN et al., 1996) e em níveis populacionais elevados acarretando prejuízos econômicos (BROWN; FROHLICH; ROSELL, 1995). 
A mosca-branca B. tabaci biótipo B também transmite os geminivírus, Squash leaf curl virus (SLCV) e Watermelon chlorotic stunt virus (WCSV) em cultivares de C. foetidissima, $C$. maxima, C. moschata e C. pepo, ocasionando severa ondulação e manchas aneladas amarelas, tornando a folha transparente quando exposta contra o sol. Em muitos casos, as plantas, mesmo produzindo flores, não produzem frutos (BROWN; COSTA; LAEMMLEN, 1992). A espécie de begomovirus, Cucurbit leaf curl virus-Arizona (CuLRV-AZ) foi detectada infectando cucurbitáceas, dentre elas abobrinha (C. pepo), melão (Cucumis melo) e abóbora (C. maxima) transmitido por B. tabaci (BROWN et al., 2002).

Os danos ocasionados por B. tabaci biótipo B têm aumentado significativamente em diferentes regiões geográficas do Brasil e do mundo, e seu controle tem sido feito quase que exclusivamente por inseticidas e por tratos culturais. Segundo Horowitz e Ishaaya (1995) e Silva et al. (2009), B. tabaci biótipo B possui alta capacidade de apresentar resistência a muitas classes de inseticidas convencionais.

Em razão desse e de outros problemas causados pelos inseticidas no agroecossistema, táticas alternativas e menos agressivas para o manejo de moscas-brancas nas culturas vem sendo estudados. Dentre essas táticas, o uso de genótipos resistentes pode contribuir para a redução no uso de agroquímicos, reduzindo o tamanho e a atividade da população dos insetos, bem como inibindo os efeitos de seus mecanismos de alimentação e transmissão de vírus (LARA, 1991; HEINZ; ZALOM, 1995).

Dessa forma, o presente trabalho teve como objetivo avaliar genótipos de aboboreiras (Cucurbita spp.) quanto à resistência do tipo não preferência para oviposição e atratividade contra $B$. tabaci biótipo B.

\section{Material e Métodos}

Os experimentos foram conduzidos em casa de vegetação e em sala climatizada, laboratório, com temperatura de $25 \pm 2^{\circ} \mathrm{C}$, umidade relativa de $70 \pm 10 \%$ e fotofase de 12 horas.

Em casa de vegetação, 20 genótipos de aboboreira disponíveis no mercado (Tabela 1), foram semeados em vasos de polietileno de $2 \mathrm{~L}$ contendo mistura de terra de barranco, esterco de curral $(3: 1)$ e para cada vaso $6,30 \mathrm{~g}$ de NPK na formulação 4-14-8. As plantas receberam adubação nitrogenada com $1,25 \mathrm{~g}$ de sulfato de amônia a cada 15 dias. Além dos aspectos comerciais, a escolha dos genótipos foi realizada com base em ensaios preliminares e também considerando os históricos de suscetibilidade e resistência dos materiais a $B$. tabaci biótipo B. Foram semeadas cinco sementes por vaso e após a germinação, realizou-se o desbaste, deixando-se uma planta por vaso no teste com chance e duas planta por vaso no sem chance.

A criação dessa mosca-branca teve início a partir de espécimes provenientes do Setor de Entomologia do Instituto Agronômico de Campinas (IAC), previamente identificados como B. tabaci biótipo B pela Dra. Judith K. Brown, da Universidade do Arizona, EUA e recentemente confirmados através da caracterização molecular por Fontes, Colombo e Lourenção (2010) e Valle et al. (2011), que foram acondicionados em casa de vegetação. Como hospedeiras, foram utilizadas plantas de couve-manteiga, soja e tomate, acondicionadas em vasos de 2,5 L. Estes vasos foram monitorados semanalmente e as plantas deterioradas substituídas por outras sadias. 
Tabela 1. Genótipos de Cucurbita spp. avaliados quanto à resistência para B. tabaci biótipo B.

\begin{tabular}{lll}
\hline Espécie & \multicolumn{1}{c}{ Genótipo } & \multicolumn{1}{c}{ Procedência } \\
\hline \multirow{2}{*}{ C. pepo } & 'Menina Morena' & Hortec \\
& 'AF-6741' & Sakata \\
& 'Alicia AF-9354' & Sakata \\
\hline & 'Aline AF-9353' & Sakata \\
& 'Itapuã 301' & Islã \\
& 'Formosa' & Horticeres \\
& 'Novita' & Sakata \\
& 'Caserta' & Horticeres \\
& 'Golden Delight' & Rogers \\
& 'Novita Plus' & Sakata \\
& 'Tâmara' & Sakata \\
& 'Samira' & Sakata \\
\hline C. moschata & 'Canhão Seca Gigante' & Horticeres \\
& 'Nova Caravela' & Horticeres \\
& 'Bárbara 305' & Sakata \\
& 'Daiane' & Sakata \\
'Atlas' & Sakata \\
& 'Menina Brasileira' & Horticeres \\
\hline C. máxima & 'Sandy' & Sakata \\
\hline
\end{tabular}

Fonte: Elaboração dos autores.

\section{Atratividade e preferência para oviposição}

Avaliaram-se a atratividade e a preferência para oviposição da mosca-branca em 20 genótipos de Cucurbita spp. (Tabela 1) em ensaio com chance de escolha. Cada parcela foi constituída de um vaso contendo uma planta de aboboreira com o terceiro par de folhas verdadeiras desenvolvido.

Utilizaram-se 20 tratamentos (genótipos) e dez repetições, totalizando 200 parcelas. Os ensaios tiveram início quando as aboboreiras emitiram o terceiro par de folhas verdadeiras. Estes testes foram realizados em casa de vegetação, a uma temperatura média de $26,5^{\circ} \mathrm{C}$ (mínima de $20^{\circ} \mathrm{C}$ e máxima de $33^{\circ} \mathrm{C}$ ) e umidade relativa média de $71,3 \%$, em delineamento de blocos casualizados (DBC).

Os vasos contendo os genótipos foram distribuídos de forma aleatória, em círculo, no interior de gaiolas teladas $(2,0 \times 2,0 \times 2,5 \mathrm{~m})$, liberando-se do interior de um frasco, no chão, e ao centro, 100 adultos (48 horas) da mosca-branca por vaso. As plantas foram espaçadas em cerca de 20-30 cm umas das outras, evitando o contato entre as folhas. A atratividade foi avaliada $12 \mathrm{~h}, 24 \mathrm{~h}, 48 \mathrm{~h}$ e $72 \mathrm{~h}$ após a liberação, contando-se, com o auxílio de um espelho, o número de adultos presentes na superfície abaxial de duas folhas verdadeiras por planta/vaso.

Para avaliar a preferência para oviposição, após a última contagem de adultos, as duas folhas verdadeiras por parcela foram destacadas, acondicionadas em sacos plásticos e armazenadas sob refrigeração para posterior avaliação do número de ovos presentes na face abaxial, sendo calculada a média. A contagem foi realizada com auxílio de estereomicroscópio, sob aumento de 16x. Após a contagem, as áreas das folhas foram medida com auxílio de um medidor foliar LI-COR (LAI 3000A), a fim de se obter o número de ovos $/ \mathrm{cm}^{2}$ e o número de adultos $/ \mathrm{cm}^{2}$. 
$\mathrm{O}$ índice de atratividade foi calculado através da fórmula: $\mathrm{IA}=2 \mathrm{~T} /(\mathrm{T}+\mathrm{P})$, onde $\mathrm{IA}=$ índice de atratividade; $\mathrm{T}=\mathrm{n}^{\mathrm{o}}$ de insetos atraídos para $\mathrm{O}$ genótipo avaliado e $\mathrm{P}=\mathrm{n}^{\mathrm{o}}$ de insetos atraídos para o genótipo padrão suscetível ('Novita'). Os valores de IA variam entre zero e dois, sendo que IA $=1$ indica atração semelhante entre o genótipo avaliado e o padrão suscetível, IA $<1$ corresponde a uma menor atração pelo genótipo e IA $>1$ indica maior atração pelo genótipo avaliado em relação ao padrão. O genótipo 'Novita' foi adotado como padrão suscetível, uma vez que se trata de um material comercial, amplamente cultivado, e já utilizado como padrão comparativo em trabalho com moscabranca B. tabaci biótipo B (BALDIN et al., 2009). Os genótipos foram classificados comparando-se o índice obtido no genótipo avaliado com o do padrão, adotando-se o erro padrão (EP) da média do ensaio para sua diferenciação (BALDIN; LARA 2001; BALDIN; VENDRAMIM; LOURENÇÃO, 2005; BALDIN et al., 2009; SCHLICK-SOUZ; BALDIN; LOURENÇÃO, 2011). Este índice é uma adaptação da fórmula citada por Lin, Kogan e Fisher (1990) para o índice de consumo.

Calculou-se também o índice de preferência para oviposição: $\mathrm{IPO}=[(\mathrm{T}-\mathrm{P}) /(\mathrm{T}+\mathrm{P})]$ x 100 (FENEMORE, 1980; BALDIN, VENDRAMIM; LOURENÇÃO, 2005; BALDIN et al., 2007; SCHLICK-SOUZ; BALDIN; LOURENÇÃO, 2011), onde $T=n^{\circ}$ de ovos contados no tratamento avaliado e $\mathrm{P}=\mathrm{n}^{\mathrm{o}}$ de ovos contados no genótipo padrão suscetível ('Novita'). O índice varia de +100 (muito estimulante) até -100 (total deterrência), sendo o valor 0 indicativo de neutralidade. A classificação dos genótipos foi feita a partir da comparação das médias de ovos dos tratamentos com a média do genótipo padrão, levando-se em consideração o erro padrão da média do ensaio para sua diferenciação.

Os dados obtidos em todos os ensaios foram submetidos ao teste de Kolmogorov-Smirnov para verificar se apresentavam distribuição normal. Quando isso ocorreu, foi utilizado o teste Snedcor (F). Quando os dados não apresentavam normalidade estes foram previamente transformados em $(\mathrm{x}+$ $0,5)^{1 / 2}$ e arco seno de $(x+0,5)^{1 / 2}$ para normalizá-los. Para as variáveis dependentes, em que o teste $\mathrm{F}$ da ANAVA (Banzatto e Kronka, 1989) foi significativo $(\mathrm{P}<0,05)$, empregou-se o teste de Tukey para comparação das médias dos tratamentos a $5 \%$ de significância. Para análise, foi utilizado o programa estatístico Stat 3.1 (Sigma Stat 3.1 for Windows, 2004).

\section{Resultados e Discussão}

\section{Atratividade para adultos de B. tabaci biótipo B}

$\mathrm{Na}$ avaliação de 12 horas (Tabela 2), verificouse que os genótipos 'Sandy' $\left(0,22\right.$ adultos $\left./ \mathrm{cm}^{2}\right)$ e 'Daiane' $\left(0,23\right.$ adultos/ $\left.\mathrm{cm}^{2}\right)$ apresentaram as menores médias de atratividade para adultos de $B$. tabaci biótipo B, seguido dos genótipos 'Formosa', 'Novita Plus', 'Atlas', 'Canhão Seca Gigante' e 'Bárbara 305' e diferindo de 'Golden Delight', que apresentou a maior média de atratividade. Após 24 horas, os genótipos Sandy' e 'Daiane mantiveram-se como menos atrativos, com 0,20 e 0,21 adultos $/ \mathrm{cm}^{2}$, respectivamente, enquanto os genótipos 'Golden Delight', 'Aline AF 9353' e 'Alícia AF 9354' apresentaram as maiores médias de atratividade, com $1,25,1,25$ e 1,22 adultos $/ \mathrm{cm}^{2}$, respectivamente, diferindo dos demais genótipos. Com 48 horas da infestação, verificou-se baixa atratividade aos adultos nos genótipos 'Sandy'e 'Daiane' (ambos com 0,14 adultos $\left./ \mathrm{cm}^{2}\right)$ e 'Formosa' (0,20 adultos/ $\mathrm{cm}^{2}$ ); ainda nessa avaliação, as maiores médias de atratividade foram observadas em 'Golden Delight' (0,92 adultos), 'Alícia AF 9354' (0,88 adultos) e 'Aline AF 9353' (0,87 adultos). Na última avaliação (72 horas), a atratividade variou de 0,08 a 0,75 adultos $/ \mathrm{cm}^{2}$, sendo os genótipos menos atrativos 'Sandy', 'Formosa', 'Daiane' e 'Bárbara 305' (os três com 0,08 adultos), enquanto os mais atrativos foram 'Golden Delight' (0,75 adultos), 'Samira' (0,61 adultos), 'Aline AF 9353' (0,58 adultos), 'Menina Morena' (0,57 adultos) e AF 6741' (0,54 adultos). 
Tabela 2. Médias ( $\pm \mathrm{EP})$ de atratividade (adultos $/ \mathrm{cm}^{2}$ ) de B. tabaci biótipo B por genótipos de Cucurbita spp., em teste com chance de escolha no interior de casa de vegetação.

\begin{tabular}{|c|c|c|c|c|c|}
\hline \multicolumn{6}{|c|}{${ }^{1}$ Número de adultos $/ \mathrm{cm}^{2}$} \\
\hline Genótipo & $12 \mathrm{~h}$ & $24 \mathrm{~h}$ & $48 \mathrm{~h}$ & $72 \mathrm{~h}$ & Média \\
\hline 'Golden Delight' & $0,92 \pm 0,12 \mathrm{a}$ & $1,25 \pm 0,17 \mathrm{a}$ & $0,92 \pm 0,18 \mathrm{a}$ & $0,75 \pm 0,17 \mathrm{a}$ & $0,96 \pm 0,14 \mathrm{a}$ \\
\hline 'Aline AF 9353' & $0,55 \pm 0,07 \mathrm{abc}$ & $1,25 \pm 0,16 \mathrm{a}$ & $0,87 \pm 0,10 \mathrm{a}$ & $0,58 \pm 0,07 \mathrm{abc}$ & $0,81 \pm 0,07 \mathrm{a}$ \\
\hline 'Alicia AF 9354' & $0,69 \pm 0,05 \mathrm{ab}$ & $1,22 \pm 0,18 \mathrm{a}$ & $0,88 \pm 0,06 \mathrm{a}$ & $0,36 \pm 0,05$ bcde & $0,79 \pm 0,07 \mathrm{ab}$ \\
\hline 'AF-6741' & $0,64 \pm 0,07 \mathrm{ab}$ & $0,58 \pm 0,08 \mathrm{bc}$ & $0,53 \pm 0,08 \mathrm{ab}$ & $0,54 \pm 0,07 \mathrm{abc}$ & $0,57 \pm 0,04 \mathrm{bc}$ \\
\hline 'Nova Caravela' & $0,68 \pm 0,13 \mathrm{ab}$ & $0,67 \pm 0,11 \mathrm{~b}$ & $0,57 \pm 0,11 \mathrm{ab}$ & $0,31 \pm 0,04$ bcdef & $0,55 \pm 0,05 \mathrm{~cd}$ \\
\hline 'Samira' & $0,61 \pm 0,04 \mathrm{ab}$ & $0,52 \pm 0,10 \mathrm{bc}$ & $0,47 \pm 0,06 a b c$ & $0,61 \pm 0,10 \mathrm{ab}$ & $0,55 \pm 0,04 \mathrm{~cd}$ \\
\hline 'Novita' & $0,65 \pm 0,09 \mathrm{ab}$ & $0,57 \pm 0,03 \mathrm{bc}$ & $0,51 \pm 0,08 \mathrm{ab}$ & $0,47 \pm 0,07$ bcde & $0,55 \pm 0,04 \mathrm{~cd}$ \\
\hline 'Menina Morena' & $0,67 \pm 0,05 \mathrm{ab}$ & $0,57 \pm 0,06 \mathrm{bc}$ & $0,36 \pm 0,09 \mathrm{bc}$ & $0,57 \pm 0,04 \mathrm{abc}$ & $0,54 \pm 0,03 \mathrm{cde}$ \\
\hline 'Exposição' & $0,61 \pm 0,11 \mathrm{ab}$ & $0,59 \pm 0,07 \mathrm{bc}$ & $0,51 \pm 0,05 \mathrm{ab}$ & $0,44 \pm 0,07 \mathrm{abcd}$ & $0,53 \pm 0,04 \mathrm{cdef}$ \\
\hline 'Caserta' & $0,58 \pm 0,11 \mathrm{abc}$ & $0,58 \pm 0,10 \mathrm{bc}$ & $0,49 \pm 0,14 \mathrm{bc}$ & $0,46 \pm 0,03 \mathrm{abcd}$ & $0,53 \pm 0,0,05$ cdef \\
\hline 'Itapuã 301' & $0,51 \pm 0,11 \mathrm{abc}$ & $0,57 \pm 0,13 \mathrm{bc}$ & $0,44 \pm 0,10 \mathrm{bc}$ & $0,47 \pm 0,06 \mathrm{abcd}$ & $0,50 \pm 0,05 \mathrm{cdef}$ \\
\hline ‘Tâmara’' & $0,51 \pm 0,04 \mathrm{abc}$ & $0,48 \pm 0,09 \mathrm{bc}$ & $0,52 \pm 0,08 \mathrm{ab}$ & $0,23 \pm 0,04 \mathrm{def}$ & $0,44 \pm 0,04$ cdefg \\
\hline 'Menina Brasileira' & $0,52 \pm 0,10 \mathrm{abc}$ & $0,38 \pm 0,05 \mathrm{bc}$ & $0,30 \pm 0,05 \mathrm{bc}$ & $0,29 \pm 0,06 \mathrm{cdef}$ & $0,37 \pm 0,03 \mathrm{cdefgh}$ \\
\hline 'Novita Plus' & $0,36 \pm 0,02 \mathrm{bc}$ & $0,43 \pm 0,03 \mathrm{bc}$ & $0,42 \pm 0,07 \mathrm{bc}$ & $0,24 \pm 0,02 \mathrm{def}$ & $0,36 \pm 0,02$ cdefgh \\
\hline 'Atlas' & $0,37 \pm 0,04 \mathrm{bc}$ & $0,41 \pm 0,08 \mathrm{bc}$ & $0,36 \pm 0,06 \mathrm{bc}$ & $0,29 \pm 0,04 \mathrm{cdef}$ & $0,36 \pm 0,03$ defgh \\
\hline $\begin{array}{l}\text { 'Canhão Seca } \\
\text { Gigante' }\end{array}$ & $0,39 \pm 0,03 \mathrm{bc}$ & $0,40 \pm 0,05 \mathrm{bc}$ & $0,31 \pm 0,05 \mathrm{bc}$ & $0,24 \pm 0,04 \mathrm{def}$ & $0,33 \pm 0,02$ efgh \\
\hline 'Bárbara 305' & $0,47 \pm 0,11 \mathrm{bc}$ & $0,36 \pm 0,03 \mathrm{bc}$ & $0,34 \pm 0,05 \mathrm{bc}$ & $0,13 \pm 0,02$ ef & $0,32 \pm 0,04 \mathrm{fgh}$ \\
\hline 'Formosa' & $0,33 \pm 0,05 \mathrm{bc}$ & $0,39 \pm 0,09 \mathrm{bc}$ & $0,20 \pm 0,02 \mathrm{c}$ & $0,08 \pm 0,01 \mathrm{f}$ & $0,25 \pm 0,03 \mathrm{gh}$ \\
\hline 'Daiane' & $0,23 \pm 0,05 \mathrm{c}$ & $0,21 \pm 0,04 \mathrm{c}$ & $0,14 \pm 0,02 \mathrm{c}$ & $0,08 \pm 0,02 \mathrm{f}$ & $0,16 \pm 0,02 \mathrm{~h}$ \\
\hline 'Sandy' & $0,22 \pm 0,04 \mathrm{c}$ & $0,20 \pm 0,04 \mathrm{c}$ & $0,14 \pm 0,02 \mathrm{c}$ & $0,08 \pm 0,02 \mathrm{f}$ & $0,16 \pm 0,02 \mathrm{~h}$ \\
\hline $\mathrm{CV}(\%)$ & 12,06 & 13,07 & 12,53 & 10,37 & 12,70 \\
\hline
\end{tabular}

${ }^{1}$ Médias seguidas de mesma letra, na coluna, não diferem significativamente entre si pelo teste de Tukey (P $\left.\leq 0,05\right)$. Dados originais; para análise, os dados foram transformados em $(\mathrm{x}+0,5)^{1 / 2}$.

Fonte: Elaboração dos autores.

Considerando-se a média geral de adultos atraídos durante as quatro avaliações (Tabela 2), nota-se que 'Sandy' $(0,16)$, 'Daiane' $(0,16)$ e 'Formosa' $(0,25)$ revelaram-se os menos atrativos aos adultos dos insetos. Os genótipos 'Golden Delight' e 'Aline AF 9353', seguido do genótipo 'Alícia AF 9354' foram os mais atrativos, com médias de 0,96; 0,81 e 0,79 adultos $/ \mathrm{cm}^{2}$, revelando-se os mais suscetíveis aos adultos. Alves, Lourenção e Melo (2005), em experimento envolvendo dezesseis genótipos de aboboreiras (Cucurbita spp), também verificaram a alta atratividade do genótipo 'Golden Delight' aos adultos desse inseto, e a baixa atratividade do genótipo 'Bárbara'. Em experimentos de campo, Baldin et al. (2009) avaliaram a atratividade de $B$. tabaci biótipo $\mathrm{B}$ em oito genótipos de $C$. pepo aos
15, 30 e 45 dias após a emergência e reportaram baixa atratividade no genótipo 'Sandy' para essa mosca-branca, corroborando os dados do presente trabalho.

A ocorrência de diferentes níveis de atratividade a adultos de $B$. tabaci biótipo $\mathrm{B}$ em função do genótipo vem sendo relatada também para outras culturas de importância econômica. Em meloeiro, avaliando-se 32 cultivares, Coelho et al. (2009) detectaram diferenças na atratividade em relação a adultos dessa mosca-branca, constatando menor atratividade em 'Neve' $\left(0,6\right.$ adulto $\left./ 10 \mathrm{~cm}^{2}\right)$, enquanto a cultivar 'Nilo' foi a mais infestada (5,6 adultos $\left./ 10 \mathrm{~cm}^{2}\right)$. Em experimento de casa de vegetação com 24 genótipos de batata, Silva et al. (2008) verificaram que os genótipos NYL 235-4 e 
IAC-1966 apresentaram maior número de adultos, diferindo de 'Achat', 'Aracy Ruiva' e 'Monte Bonito', com menor atratividade. Valle e Lourenção (2002), avaliando 20 genótipos de soja, verificaram também diferenças na atratividade, sendo que dentre os menos atrativos, destacaram-se 'IAC 17' e 'IAC 19'.

Índice de atratividade para adultos de B. tabaci biótipo $B$

Com base no índice de atratividade obtido após 12 horas da liberação (Figura 1), 'Sandy', 'Daiane', 'Formosa', 'Novita Plus', 'Atlas', 'Canhão Seca Gigante', 'Bárbara 305', 'Tâmara', 'Itapuã 301' e 'Menina Brasileira' foram classificados como repelentes em comparação ao padrão suscetível ('Novita'). De maneira oposta, o genótipo 'Golden Delight' foi considerado atrativo aos adultos. Já os demais genótipos foram considerados neutros em relação à 'Novita'.
Pelo índice de atratividade calculado após 24 horas de ensaio (Figura 2), 'Sandy', 'Daiane', 'Bárbara 305', 'Menina Brasileira', 'Formosa', 'Canhão Seca Gigante', 'Atlas', 'Novita Plus' e 'Tâmara' foram classificados como repelentes em relação ao padrão ('Novita'). 'Golden Delight', 'Aline AF 9353' e 'Alícia AF 9354' foram considerados atrativos e os demais obtiveram índices semelhantes ao do padrão, sendo classificados como neutros.

O índice de atratividade com 48 horas (Figura 3) classificou 'Sandy', 'Daiane', 'Formosa', 'Menina Brasileira', 'Canhão Seca Gigante', 'Bárbara 305', 'Atlas', 'Menina Morena', 'Novita Plus' e 'Itapuã 301' como repelentes. 'Golden Delight', 'Aline AF 9353' e 'Alícia AF 9354' foram atrativos, enquanto que os demais foram neutros em relação ao genótipo padrão suscetível.

Figura 1. Índice de atratividade de adultos de B. tabaci biótipo B e classificação de genótipos de Cucurbita spp., após 12 horas de teste com chance de escolha em casa de vegetação.

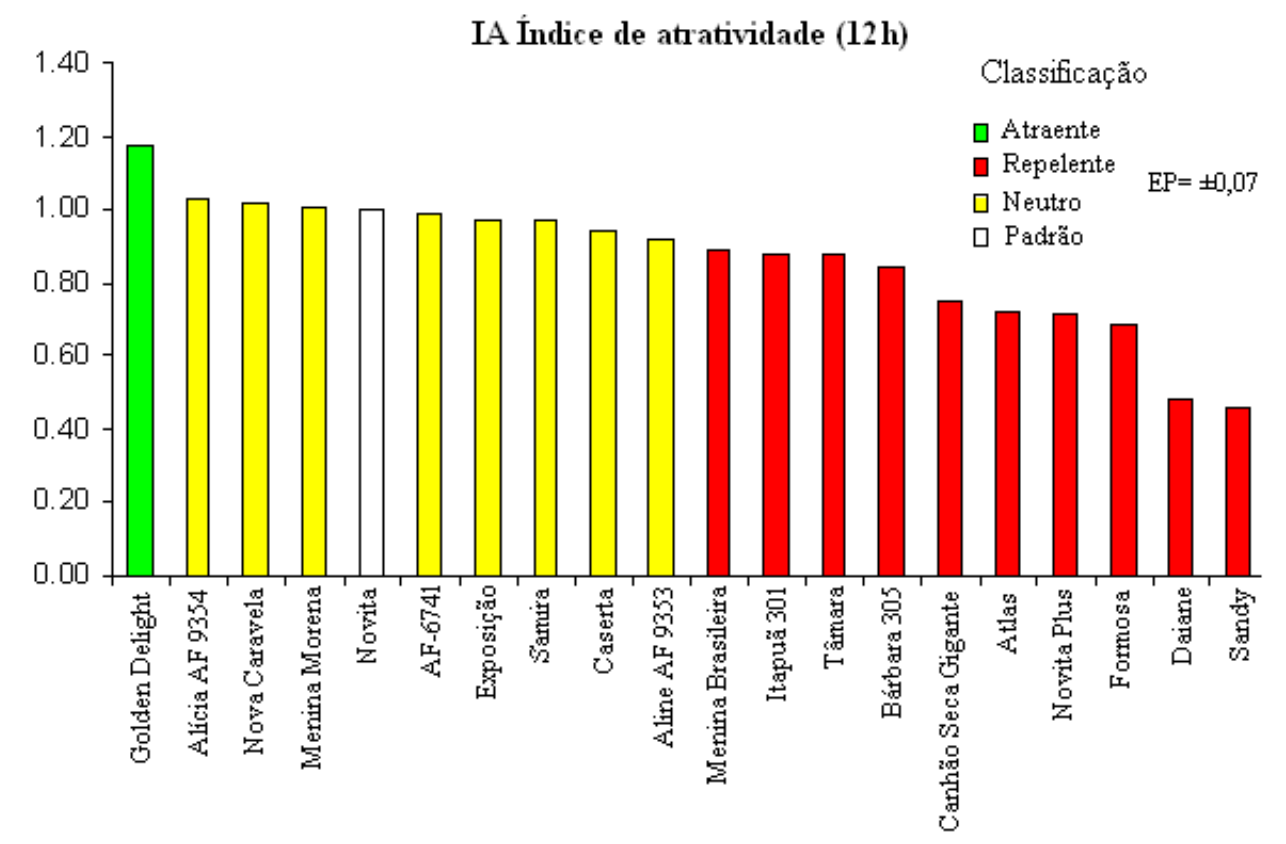

Fonte: Elaboração dos autores. 
Figura 2. Índice de atratividade de adultos de B. tabaci biótipo B e classificação de genótipos de Cucurbita spp., após 24 horas de teste com chance de escolha em casa de vegetação.

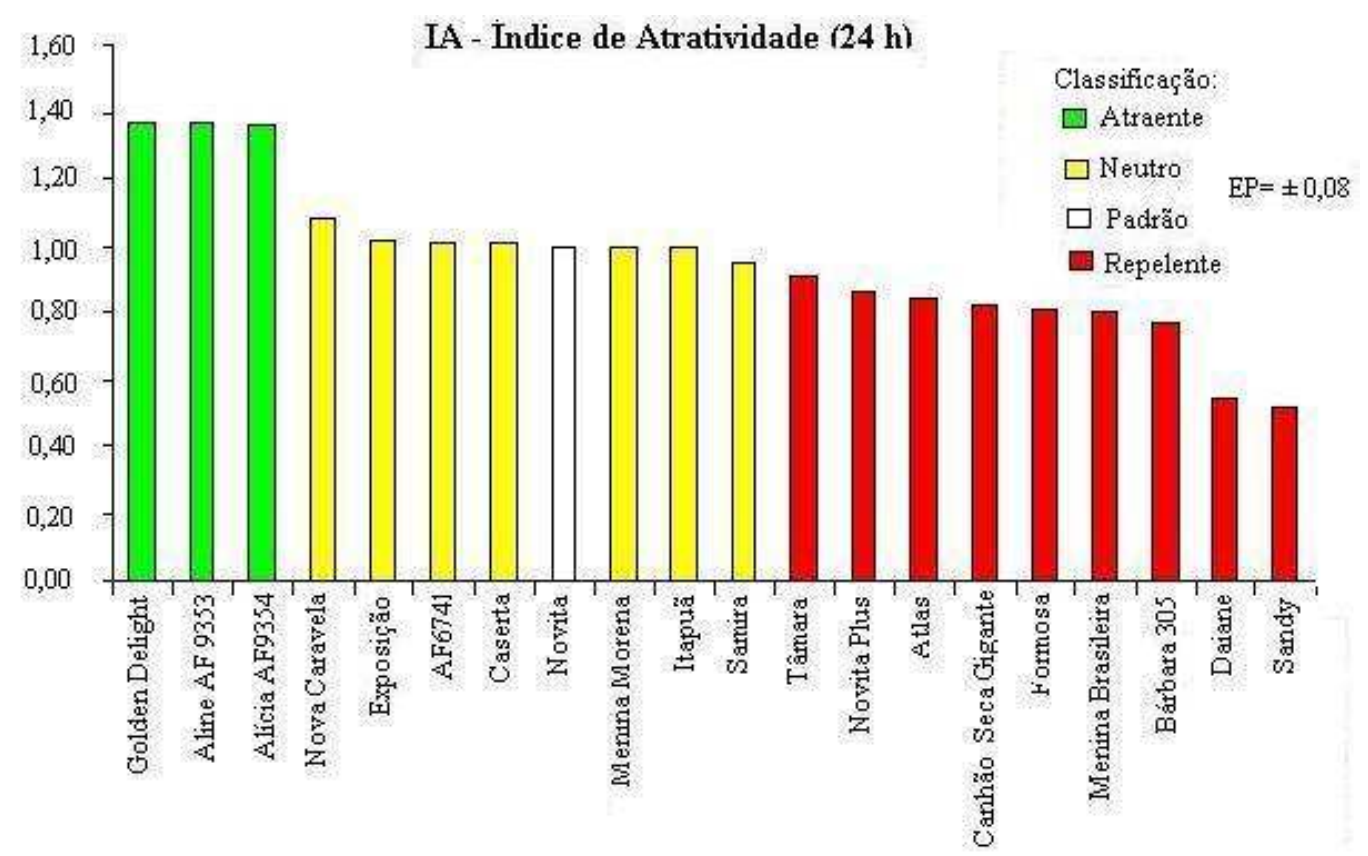

Fonte: Elaboração dos autores.

Figura 3. Índice de atratividade de adultos de B. tabaci biótipo B e classificação de genótipos de Cucurbita spp., após 48 horas de teste com chance de escolha em casa de vegetação.

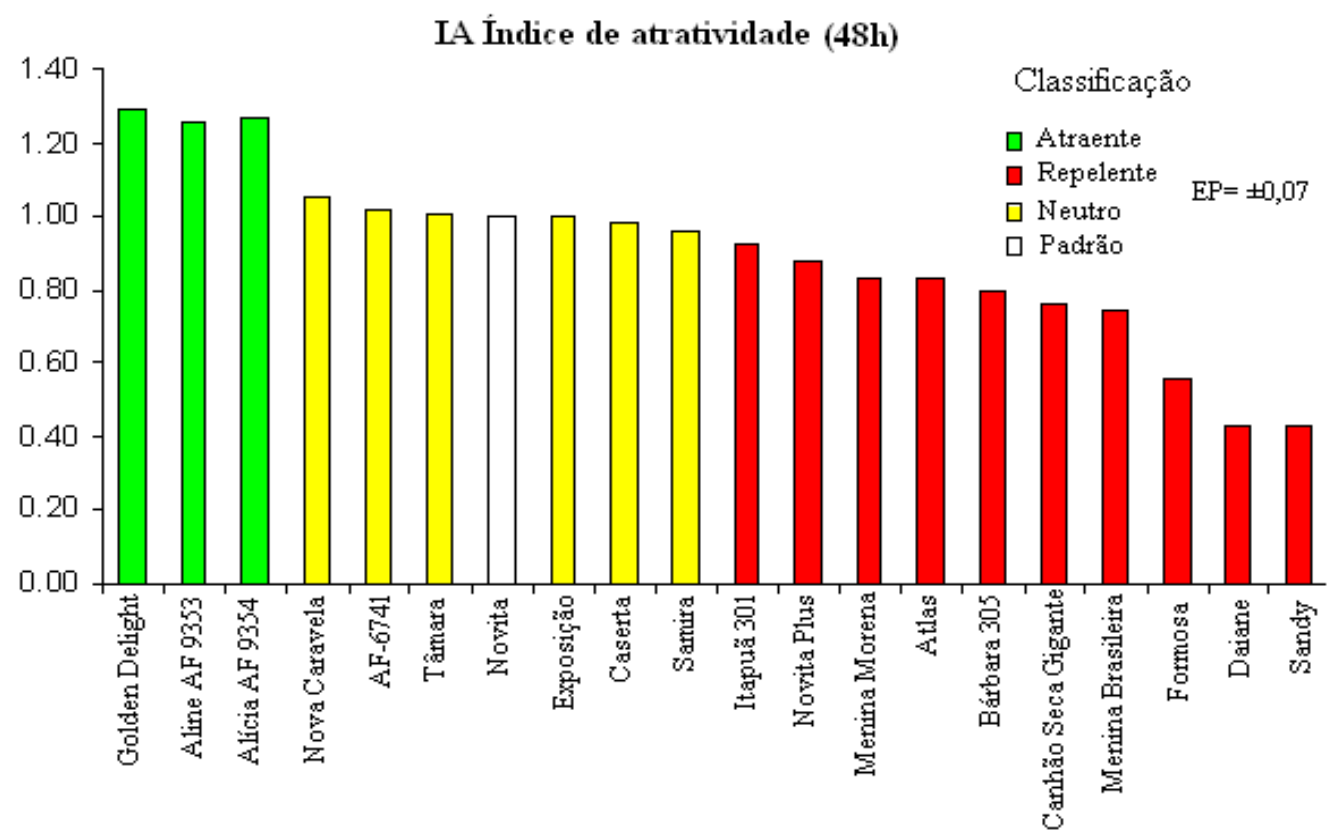

Fonte: Elaboração dos autores. 
Com 72 horas de ensaio (Figura 4), o índice classificou como repelentes os genótipos 'Sandy', 'Daiane' 'Formosa', 'Bárbara 305', 'Tâmara', 'Canhão Seca Gigante', 'Novita Plus', 'Atlas',
'Menina Brasileira' e 'Nova Caravela'. Os genótipos 'Golden Delight', 'Samira' e 'Aline AF 9353' foram classificados como atraentes e os demais foram neutros ou semelhantes ao padrão 'Novita'.

Figura 4. Índice de atratividade de adultos de B. tabaci biótipo B e classificação de genótipos de Cucurbita spp., após 72 horas de teste com chance de escolha em casa de vegetação.

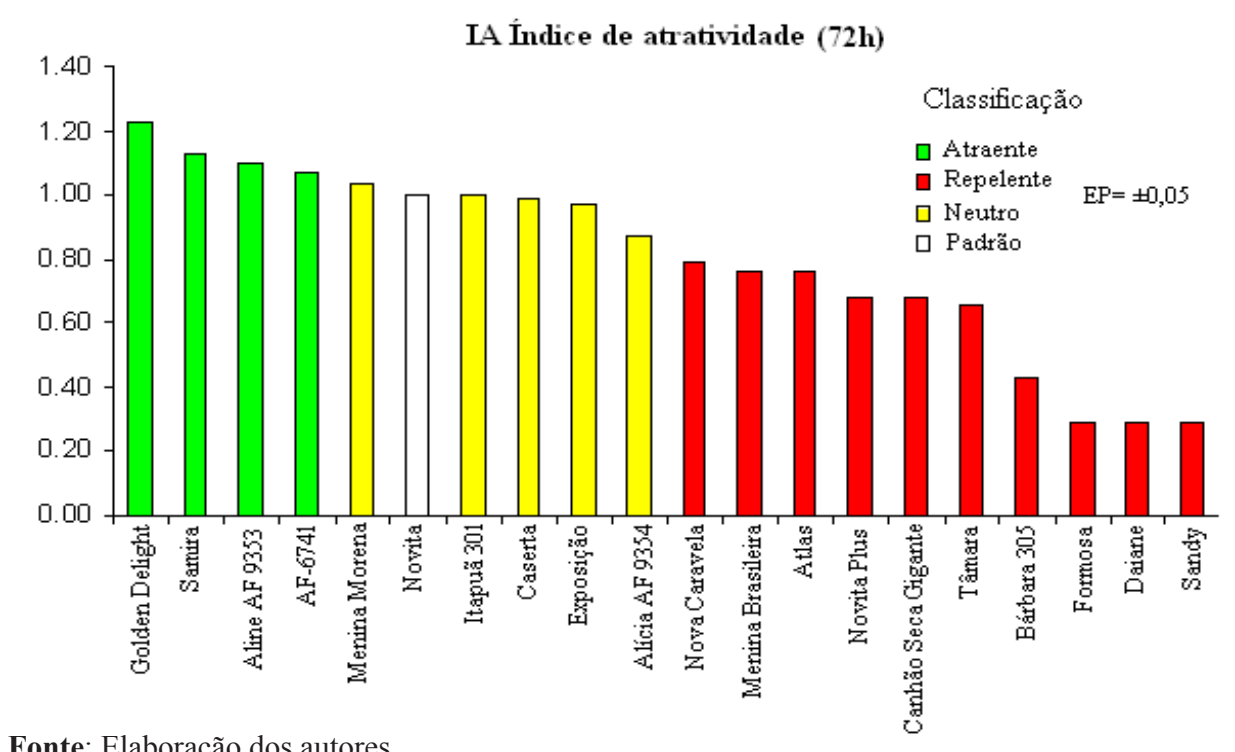

Fonte: Elaboração dos autores.

Mediante análise geral dos índices de atratividade dos genótipos para os adultos de B. tabaci biótipo B, verifica-se que 'Golden Delight' é o mais atrativo. Entre os classificados como repelentes destacamse 'Sandy', 'Daiane', 'Formosa', 'Novita Plus', 'Atlas', 'Bárbara 305', 'Canhão Seca Gigante' e 'Menina Brasileira'. Segundo Baldin et al. (2009) e Alves et al. (2006), esse comportamento pode ser devido a fatores repelentes que afetam a atratividade e a permanência da mosca-branca sobre as folhas. Provavelmente os genótipos com maior repelência apresentam cores ou mesmo substâncias químicas voláteis indesejáveis aos insetos. As folhas dos genótipos 'Sandy' e 'Daiane' apresentam tonalidade verde mais escura, quando comparadas as dos demais. No trabalho de Coelho et al. (2009) há avaliação de cores das folhas por meio de colorímetro, cujos resultados mostram a associação de tons mais escuros com a menor atratividade.
Segundo Beck e Schoonhoven (1980), a maioria das espécies de moscas-brancas e afideos são mais atraídas por superfícies vegetais amareladas, o que poderia explicar a repelência desses dois genótipos ao inseto. Segundo Vendramim e Guzzo (2009), a cor do substrato vegetal é importante para a seleção hospedeira: contudo, em razão da variação de percepção das cores pelo homem e pelos insetos, é difícil a realização de trabalhos de resistência explorando esse fator. Outros fatores, como densidade e tipo de tricomas (CHANNARAYAPPA; MUNIYAPPA; FRIST, 1992; BARTEN et al., 1994; FANCELLI et al., 2003, BALDIN; VENDRAMIM; LOURENÇÃO, 2005, BALDIN et al., 2009; VALLE; LOURENÇÃO; PINHEIRO, 2012), além de compostos químicos podem ser explorados na busca pelas causas da menor atratividade por alguns dos genótipos. 


\section{Preferência para oviposição}

$\mathrm{Na}$ avaliação de oviposição em teste de livre escolha (Tabela 3), verificou-se que os genótipos 'Nova Caravela' e 'Golden Delight' apresentaram maior média de oviposição, com médias de 4,56 e 3,38 ovos $/ \mathrm{cm}^{2}$ respectivamente. 'Sandy' $\left(0,99\right.$ ovos $\left./ \mathrm{cm}^{2}\right)$, 'Exposição' (1,01), 'Daiane' (1,02), 'Atlas'(1,02), 'Tâmara'(1,02) e 'Formosa' (1,08) apresentaram as mais baixas médias de oviposição, indicando a ocorrência de não-preferência para oviposição.

Avaliando a preferência para oviposição de B. tabaci biótipo B em teste com chance de escolha em dezesseis genótipos de Cucurbita spp., Alves, Lourenção e Melo (2005) verificaram que 'Tetsukabuto'(31,5 ovos $\left./ 10 \mathrm{~cm}^{2}\right)$ apresentou maior preferência para oviposição sendo que os genótipos 'Caravela', 'Atlanta AG-303' e 'Golden Dawn III' também apresentaram altas médias. Os genótipos menos ovipositados foram 'Novita' e 'Atlas' (ALVES; LOURENÇÃO; MELO, 2005), confirmando o presente trabalho, em que 'Atlas' está entre os menos preferidos para oviposição com chance de escolha. Ratificando também, Baldin e Beneduzzi (2010), num mesmo teste com oito genótipos de C. pepo em casa de vegetação, verificaram que os genótipos 'Sandy', 'Bianca' e 'Novita Plus' foram os menos ovipositadas.

De acordo com o IPO, (Tabela 3), "Nova Caravela', 'Golden Delight', 'Aline AF 9353' e 'Samira' são considerados estimulantes; enquanto que os genótipos 'Sandy' $(-26,94)$, 'Exposição' $(-26,00), \quad$ 'Daiane' (-25,55), 'Atlas' (-25,55), 'Tâmara' (-22,86), 'Formosa' $(-22,86)$, 'Menina Morena' $(-15,44)$ e 'Itapuã 301' $(-15,04)$ foram considerados deterrentes. Os demais genótipos foram neutros em comparação com 'Novita'.

Tabela 3. Número médio ( $( \pm \mathrm{EP})$ de ovos $/ \mathrm{cm}^{2}$ de $B$. tabaci biótipo B em folhas de genótipos de Cucurbita spp., índice de preferência para oviposição (IPO) e classificação, avaliados em teste com chance de escolha, em casa de vegetação.

\begin{tabular}{|c|c|c|c|}
\hline \multirow{2}{*}{ Genótipo } & \multirow{2}{*}{ Número de ovos $/ \mathrm{cm}^{2}$} & \multicolumn{2}{|c|}{ Índice de preferência para oviposição } \\
\hline & & \multicolumn{2}{|c|}{ IPO $( \pm \mathrm{EP})^{1}$ Classificação } \\
\hline 'Nova Caravela' & $4,56 \pm 1,16 \mathrm{a}$ & $45,22 \pm 12,78$ & Estimulante \\
\hline 'Golden Delight' & $3,38 \pm 0,77 \mathrm{ab}$ & $32,55 \pm 12,78$ & Estimulante \\
\hline 'Aline AF9353' & $3,02 \pm 0,77 \mathrm{abc}$ & $27,43 \pm 12,78$ & Estimulante \\
\hline 'Samira' & $2,76 \pm 0,60 \mathrm{abc}$ & $23,21 \pm 12,78$ & Estimulante \\
\hline 'Alicia AF 9354' & $2,23 \pm 0,52 \mathrm{abc}$ & $11,38 \pm 12,78$ & Neutro \\
\hline 'Bárbara 305' & $2,06 \pm 0,35 \mathrm{abc}$ & $8,99 \pm 12,78$ & Neutro \\
\hline 'Canhão Seca Gigante' & $1,98 \pm 0,58 a b c$ & $7,03 \pm 12,78$ & Neutro \\
\hline 'Novita Plus' & $1,95 \pm 0,56 \mathrm{bc}$ & $6,26 \pm 12,78$ & Neutro \\
\hline 'AF 6741' & $1,86 \pm 0,29 \mathrm{bc}$ & $3,91 \pm 12,78$ & Neutro \\
\hline 'Novita' & $1,72 \pm 0,36 \mathrm{bc}$ & $0,00 \pm 12,78$ & Padrão \\
\hline 'Caserta' & $1,68 \pm 0,49 \mathrm{bc}$ & $-1,80 \pm 12,78$ & Neutro \\
\hline 'Menina Brasileira' & $1,64 \pm 0,42 \mathrm{bc}$ & $-2,38 \pm 12,78$ & Neutro \\
\hline 'Itapuã 301' & $1,27 \pm 0,34 \mathrm{bc}$ & $-15,05 \pm 12,78$ & Deterrente \\
\hline 'Menina Morena' & $1,26 \pm 0,21 \mathrm{bc}$ & $-15,44 \pm 12,78$ & Deterrente \\
\hline 'Formosa' & $1,08 \pm 0,19 \mathrm{c}$ & $-22,86 \pm 12,78$ & Deterrente \\
\hline 'Tâmara' & $1,08 \pm 0,18 \mathrm{c}$ & $-22,86 \pm 12,78$ & Deterrente \\
\hline 'Atlas' & $1,02 \pm 0,36 \mathrm{c}$ & $-25,55 \pm 12,78$ & Deterrente \\
\hline 'Daiane' & $1,02 \pm 0,07 \mathrm{c}$ & $-25,55 \pm 12,78$ & Deterrente \\
\hline 'Exposição’ & $1,01 \pm 0,10 \mathrm{c}$ & $-26,00 \pm 12,78$ & Deterrente \\
\hline 'Sandy' & $0,99 \pm 0,08 \mathrm{c}$ & $-26,94 \pm 12,78$ & Deterrente \\
\hline $\mathrm{CV}(\%)$ & 25,06 & - & - \\
\hline
\end{tabular}

Médias seguidas de mesma letra, na coluna, não diferem significativamente entre si pelo teste de Tukey $(\mathrm{P} \leq 0,05)$. Dados originais. Para análise, os dados foram transformados em $(\mathrm{x}+0,5)^{1 / 2}$.

${ }^{1} \mathrm{IPO}=[(\mathrm{T}-\mathrm{P}) /(\mathrm{T}+\mathrm{P})] \mathrm{x} 100$. IPO varia de +100 (muito estimulante) até -100 (total deterrência), sendo o valor 0 indicativo de neutralidade.

Fonte: Elaboração dos autores. 


\section{Conclusões}

$\mathrm{O}$ índice de atratividade (IA) classificou o genótipo 'Golden Delight' como o mais atrativo a adultos de $B$. tabaci biótipo $\mathrm{B}$, e entre os repelentes destacaram-se 'Sandy', 'Daiane', 'Formosa', 'Novita Plus', 'Atlas', 'Bárbara 305', 'Canhão Seca Gigante' e 'Menina Brasileira'.

Os genótipos 'Nova Caravela', 'Golden Delight', 'Aline AF 9353' e 'Samira' são consideradas estimulantes através do índice de preferência para oviposição (IPO); enquanto que os genótipos 'Sandy', 'Exposição', 'Daiane', 'Atlas', 'Tâmara', 'Formosa', 'Menina Morena' e 'Itapuã 301' foram considerados deterrentes.

\section{Agradecimentos}

Os autores agradecem a Coordenadoria de Aperfeiçoamento de Pessoal de Nível Superior (CAPES) pela bolsa de doutorado concedida ao primeiro autor

\section{Referências}

ALVES, A. C.; LOURENÇÃO, A. L.; MELO, A. M. T.; MATOS, E. S. Atratividade e preferência para oviposição de Trialeurodes vaporariorum em genótipos de aboboreira. Horticultura Brasileira, Brasília, v. 24, n. 4, p. 446-449, 2006.

ALVES, A. C.; LOURENÇ̃̃O, A. L.; MELO, A. M. T. Resistência de genótipos de aboboreira a Bemisia tabaci (Genn.) Biótipo B (Hemiptera: Aleyrodidae). Neotropical Entomology, Londrina, v. 34, n. 6, p. 973-9, 2005.

BALDIN, E. L. L.; BENEDUZZI, R. A. Characterization of antibiosis and antixenosis to the whitefly silverleaf Bemisia tabaci B biotype (Hemiptera: Aleyrodidae) in several squash varieties. Journal of Pest Science, Heidelberg, v. 83, n. 3, p. 223-229, 2010.

BALDIN, E. L. L.; SOUZA, D. R.; SOUZA, E. S.; BENEDUZZI, R. A. Controle de mosca-branca com extratos vegetais, em tomateiro cultivado em casa-devegetação. Horticultura Brasileira, Brasília, v. 25, n. 4, p. 602-606, 2007.
BALDIN, E. L. L.; LARA, F. M. Atratividade e consumo foliar por adultos de Diabrotica speciosa (Germ.) (Coleoptera: Chrysomelidae) em Diferentes Genótipos de Abóbora. Neotropical Entomology, Londrina, v. 30, n. 4, p. 675-679, 2001.

BALDIN, E. L. L.; VENDRAMIM, J. D.; LOURENÇÃO, A. L. Resistência de genótipos de tomateiro à moscabranca Bemisia tabaci (Gennadius) biótipo B (Hemiptera: Aleyrodidae). Neotropical Entomology, Londrina, v. 34, n. 3, p. 435-441, 2005.

BALDIN, E.L.L.; BENEDUZZI, R. A.; SOUZA, D. R.; SOUZA, E. S. Resistência de genótipos de abobrinha a Bemisia tabaci (Genn.) biótipo B. Neotropical Entomology, Londrina, v. 38, n. 4, p. 526-530, 2009.

BARTEN, J. H. M.; THOMÉ, C. H.; STEVENS, M. R.; SCHUSTER, D. J.; SCOTT, J. W.; CHAMBLISS, O. L. Evaluating resistance in tomato to the silverleaf whitefly, Bemisia argentifolii. Phytoparasitica, Bet Dagan, v. 22, n. 4, p. 330-331, 1994.

BECK, S. D.; SCHOONHOVEN, L. M. Insect behavior and plant resistance. In MAXWELL, F. G.; JENNINGS, P. R. (Ed.). Breeding plants resistant to insects. New York: John Wiley \& Sons, 1980. p. 116-135.

BLANCO, M. C. S. G.; GROPPO, G. A.; TESSARIOLI NETO, J. Manual da Coordenadoria de assistência técnica integrada. Campinas: Cati, 1997. 1997. v. 2, 11 p.

BROWN, J. K.; COSTA, H. S.; LAEMMLEN, F. First report of whitefly associated squash silverleaf disorder of Cucurbita in Arizona and of white streak disorder of Brassica species in Arizona and California. Plant Disease, St. Paul, v. 76, n. 4, p. 434-6, 1992.

BROWN, J. K.; FROHLICH, D. R.; ROSELL, R. C. The sweetpotato or silverleaf whiteflies: biotypes of Bemisia tabaci or a species complex? Annual Review of Entomology, Palo Alto, v. 40, n. 1, p. 511-34, 1995.

BROWN, J. K.; IDRIS, A. M.; ALTERI, C.; STENGER, D. C. Emergence of a new cucurbit-infecting begomovirus species capable of forming viable reassortants with related viruses in the Squash leaf curl virus cluster. Phytopathology, St. Louis, v. 92, n. 7, p. 734-742, 2002.

BYRNE, D. N.; BELLOWS JUNIOR, T. S. Whitefly biology. Annual Review of Entomology, Palo Alto, v. 36, n. 1, p. 431-457, 1991.

CHANNARAYAPPA, S.; MUNIYAPPA, G. V.; FRIST, R. H. Resistance of Lycopersicon species to Bemisia tabaci, a tomato leaf curl virus vector. Canadian Journal of Botany, Ottawa, v. 70, n. 11, p. 2184-2192, 1992. 
COELHO, S. A. M. P.; LOURENÇÃO, A. L.; MELO, A. M. T.; SCHAMMASS, E. A. Resistência de meloeiro a Bemisia tabaci biótipo B. Bragantia, Campinas, v. 68, n. 4, p. 1025-1035, 2009.

DE BARRO, P. J.; LIU, S.; BOYKIN, L. M.; DINSDALE, A. B. Bemisia tabaci: a statement of species status. Annual Review of Entomology, Palo Alto, v. 56, n. 1, p. 1-19, 2011.

FANCELLI, M.; VENDRAMIM, J. D.; LOURENÇÃO, A. L.; DIAS, C. T. S. Atratividade e preferência para oviposição de Bemisia tabaci (Gennadius) (Hemiptera: Aleyrodidae) biótipo B em genótipos de tomateiro. Neotropical Entomology, Londrina, v. 32, n. 2, p. 319328, 2003.

FENEMORE, P. G. Oviposition of potato tuber moth, Phthorimaea operculella Zell. (Lepidoptera: Gelechiidae); identification of host-plant factors influencing oviposition response. New Zealand Journal of Zoology, Wellington, v. 7, n. 3, p. 435-439, 1980.

FLINT, M. L. Whiteflies in California: a resource for cooperative extension. California: University of California. Statewide Integrated Pest Management Project. Division of Agriculture and Natural Resources, 1995. $200 \mathrm{p}$.

FONTES, F. H. M.; COLOMBO, C. A.; LOURENÇÃO, A. L. Caracterização molecular e divergência genética de Bemisia tabaci (Genn.) (Hemiptera: Aleyrodidae) em diferentes culturas e locais de cultivo. Neotropical Entomology, Londrina, v. 39, n. 2, p. 221-226, 2010.

FRANÇA, F. H.; VILLAS-BÔAS, G. L.; BRANCO, M. C. Ocorrência de Bemisia argentifolii Bellows \& Perring (Homoptera: Aleyrodidae) no Distrito Federal. Anais da Sociedade Entomológica do Brasil, Londrina, v. 25, n. 2, p. 369-372, 1996.

HEINZ, K. M.; ZALOM, F. G. Variation in trichomebased resistance to Bemisia argentifolii (Homoptera:' Aleyrodidae) oviposition on tomato. Journal of Economic Entomology, Lanham, v. 88, n. 5, p. 1494-1502, 1995.

HOELMER, K. A.; OSBORNE, L. S.; YOKOMI, R. $\mathrm{K}$. Association of sweetpotato whitefly with squash silverleaf. In: YOKOMI, R. K.; NARAYANAN, K. R.; SCHUSTER, D. J. (Ed.). Sweetpotato whitefly mediated vegetable disorders in Florida. Gainesville: Institute of Food and Agricultural Services, 1990. p. 5-6.

Foliage disorders in Florida associated with $\overline{\text { feeding }}$ by sweetpotato whitefly. Bemisia tabaci. Florida Entomologist, Gainesville, v. 74, n. 1, p. 162-6, 1991.
HOROWITZ, A. R.; ISHAAYA, I. Chemical control of Bemisia-management and application. In: GERLING, D.; MAYER, R. T. (Ed.). Bemisia 1995: taxonomy, biology, damage control and manegement. Andover: Intercept LtdA, 1995. p. 537-56.

LARA, F. M. Princípios de resistência de plantas a insetos. 2. ed. São Paulo: Ed. Ícone, 1991. 336 p.

LIN, H.; KOGAN, M.; FISHER, D. Induced resistance in soybean to the Mexican bean beetle (Coleoptera: Coccinellidae): comparisons of inducing factors. Environmental Entomology, College Park, v. 19, n. 6, p. 1852-1857, 1990.

LIU, T. X.; OETING, R. D. Morphological comparisons of three species of whiteflies (Homoptera: Aleyrodidae) found on greenhouse-grown plants. Georgia: The Georgia Agricultural Experiment Stations/College of Agricultural and Environmental Sciences/The University of Georgia, 1993. 11 p. (Boletim de Pesquisa, 12).

LOURENÇÃO, A. L.; NAGAI, H. Surtos populacionais de Bemisia tabaci no Estado de São Paulo. Bragantia, Campinas, v. 53, n. 1, p. 53-9, 1994.

NAGAI, H.; LOURENÇÃO, A. L.; VEGA, J.; MELO, A. M. T. Ocorrência da "folha prateada de aboboreira" associada à mosca branca (Bemisia tabaci). Horticultura Brasileira, Brasília, v. 10, n. 1, p. 62, 1992.

NORMAN, J. W.; RILEY, D. G.; STANSLY, P. A.; ELLSWORTH, P. C.; TOSCANO, N. C. Management of silverleaf whitefly: a comprehensive manual on the biology, economic impact and control tactics. Washington: USDA, 1996. $13 \mathrm{p}$.

OLIVEIRA, M. R. V.; SILVA, O. L. R. E. Mosca-branca, Bemisia argentifolli (Homoptera: Aleyrodidae) e sua ocorrência no Brasil. Brasília: Ministério da Agricultura e do Abastecimento/Departamento de Defesa e Inspeção Vegetal, 1997. 16 p. (Alerta Fitossanitário, 1).

SCHLICK-SOUZA, E. C.; BALDIN, E. L. L.; LOURENÇÃO,A. L. Variation in the host preferences and responses of Ascia monuste orseis Godart (Lepidoptera: Pieridae) to cultivars of collard greens Brassica oleracea (L.) var. acephala. Journal of Pest Science, Heidelberg, v. 84, n. 4, p. 429-436, 2011.

SIGMA STAT 3.1 FOR WINDOWS. Point Richmond: Systat Software, 2004.

SILVA, M. S.; LOURENÇÃO, A. L.; SOUZA-DIAS, J. A.; FILHO, H. S. M.; RAMOS, V. J.; SCHAMMASS, E. A. Resistance of potato genotypes (Solanum spp.) to Bemisia tabaci biotype B. Horticultura Brasileira, Brasília, v. 26, n. 2, p. 221-226, 2008. 
SILVA, L. D.; OMOTO, C.; BLEICHER, E.; DOURADO, P. M. Monitoramento da suscetibilidade a inseticidas em populações de Bemisia tabaci (Gennadius) (Hemiptera: Aleyrodidae) no Brasil. Neotropical Entomology, Londrina, v. 38, n. 1, p. 116-25, 2009.

SUMMERS, C. G.; STAPLETON, J. J. Use of UV reflective mulch to delay the colonization and reduce the severity of Bemisia argentifolii (Homoptera: Aleyrodidae) infestations in cucurbits. Crop Protection, Guildford, v. 21, n. 10, p. 921-928, 2002.

VALLE, G. E.; LOURENÇÃO, A. L. Resistência de genótipos de soja a Bemisia tabaci (Genn.) biótipo B (Hemiptera:Aleyrodidae). Neotropical Entomology, Londrina, v. 31, n. 1, p. 285-295, 2002.

VALLE, G. E.; ZUCCHI, M. I.; STABELLINI, N. S.; LOURENÇÃO, A. L.; PINHEIRO, J. B. Estrutura genética populacional de Bemisia tabaci (Gennadius) (Hemiptera: Aleyrodidae) utilizando marcadores microssatélites. Neotropical Entomology, Londrina, v. 40, n. 2, p. 204-211, 2011.

VALlE, G. E.; LOURENÇÃO, A. L.; PINHEIRO, J. B. Adult attractiveness and oviposition preference of Bemisia tabaci biotype B in soybean genotypes with different trichome density. Journal of Pest Science, Heidelberg, v. 85, n. 4, p. 443, 2012.
VAN LENTEREN, J. C.; NOLDUS, L. P. J. J. Whiteflyplant relationships: behavioral and ecological aspects. In: GERLING, D. Whiteflies: their bionomics, pest status and management. Andover: Intercept, 1990. p. 47-90.

VENDRAMIM, J. D.; GUZZO, E. C. Resistência de plantas e a bioecologia e nutrição dos insetos. In: PANIZZI, A. R.; PARRA, J. R. P. (Ed.). Bioecologia e nutrição de insetos: base para o manejo integrado de pragas. Brasília, DF: EMBRAPA Informação Tecnológica; Londrina: EMBRAPA Soja, c. 25, 2009. p. 1055-1105 p.

VILLAS BÔAS, G. L.; FRANÇA, F. H.; ÁVILA, A. C.; BEZERRA, I. C. Manejo integrado da mosca-branca Bemisia argentifolii. Brasília: EMBRAPA-CNPH, 1997. 11 p. (EMBRAPA-CNPH. Circular técnica da EMBRAPA Hortaliças, 9).

YOKOMI, R. K.; HOELMER, K. A.; OSBORNE, L. S. Relationships between the sweetpotato whitefly and the squash silverleaf disorder. Phytopathology, Saint Paul, v. 80 , n. 10 , p. 895-900, 1990a.

. Studies on etiology of squash silverleaf at Orlando. In: YOKOMI, R. K.; NARAYANAN, K. R.; SCHUSTER, D. J. (Ed.). Sweetpotato whitefly mediated vegetable disorders in Florida. Gainesville: Institute of Food and Agricultural Sciences, 1990b. p. 23-24. 
